\title{
PRELIMINARY GEOLOGIC MAP OF THE ELSINORE 7.5' QUADRANGLE, RIVERSIDE COUNTY, CALIFORNIA
}

\author{
By Douglas M. Morton ${ }^{1}$ and F. Harold Weber, $\mathrm{Jr}^{2}$ \\ Digital preparation by Rachel M. Alvarez ${ }^{2}$ and Diane Burns ${ }^{3}$ \\ Prepared in cooperation with \\ CALIFORNIA GEOLOGICAL SURVEY
}

Open-File Report OF 03-281

2003

This report is preliminary and has not been reviewed for conformity with U.S. Geological Survey editorial standards or with the North American Stratigraphic Code. Any use of trade, product, or firm names is for descriptive purposes only and does not imply endorsement by the U.S. Government. This database, identified as "Preliminary Geologic Map of the Elsinore 7.5' Quadrangle, Riverside County, California" has been approved for release and publication by the Director of the USGS.

\section{U.S. DEPARTMENT OF INTERIOR}

U.S. GEOLOGICAL SURVEY

\author{
${ }^{1}$ U.S. Geological Survey \\ Department of Earth Sciences \\ University of California \\ Riverside, CA 92521 \\ ${ }^{2}$ California Geological Survey \\ 655 South Hope St. \\ Los Angeles, CA 90017 \\ ${ }^{3}$ California Geological Survey \\ Department of Earth Sciences \\ University of California \\ Riverside, CA 92521
}




\section{TABLE OF CONTENTS}

Introduction

General

How to obtain paper plots

Database contents

Data package

Plot package

Symbols Package

Other files

Software utilities

How to obtain the digital files

How to extract the geologic map database from the tar file

Digital database

Postscript plot files

Portable document format (.pdf) files

How to convert the ARC/INFO interchange (export) files

Digital geologic map specifications

Digital compilation
Base map
Spatial resolution
Map accuracy standards
Faults and landslides
Database specifics
$\quad$ General
$\quad$ Lines
Polygons
Points

References

Appendix I

Metadata

\section{INTRODUCTION}

\section{General}

Open-File Report 03-281 contains a digital geologic map database of the Elsinore 7.5' quadrangle, Riverside County, California that includes:

1. $\quad$ ARC/INFO (Environmental Systems Research Institute, http://www.esri.com) version 7.2.1 coverages of the various elements of the geologic map.

2. A Postscript file to plot the geologic map on a topographic base, and containing a Correlation of Map Units diagram (CMU), a Description of Map Units (DMU), and an index map.

3. Portable Document Format (.pdf) files of:

a. This Readme; includes in Appendix I, data contained in els_met.txt

b. The same graphic as plotted in 2 above. Test plots have not produced precise 1:24,000scale map sheets. Adobe Acrobat page size setting influences map scale.

The Correlation of Map Units and Description of Map Units is in the editorial format of USGS Geologic Investigations Series (I-series) maps but has not been edited to comply with I-map standards. Within the geologic map data package, map units are identified by standard geologic map criteria such as formationname, age, and lithology. Where known, grain size is indicated on the map by a subscripted letter or letters following the unit symbols as follows: lg, large boulders; b, boulder; g, gravel; a, arenaceous; s, silt; c, clay; e.g. $\mathrm{Qyf}_{\mathrm{a}}$ is a predominantly young alluvial fan deposit that is arenaceous. Multiple letters are used for 
more specific identification or for mixed units, e.g., Qfy $\mathrm{sa}_{\mathrm{sa}}$ is a silty sand. In some cases, mixed units are indicated by a compound symbol; e.g., Qyf ${ }_{2 \mathrm{sc}}$.

Even though this is an Open-File Report and includes the standard USGS Open-File disclaimer, the report closely adheres to the stratigraphic nomenclature of the U.S. Geological Survey. Descriptions of units can be obtained by viewing or plotting the .pdf file ( $3 \mathrm{~b}$ above) or plotting the postscript file ( 2 above).

This Readme file describes the digital data, such as types and general contents of files making up the database, and includes information on how to extract and plot the map and accompanying graphic file. Metadata information can be accessed at http://geo-nsdi.er.usgs.gov/metadata/open-file/03-281 and is included in Appendix I of this Readme.

\section{HOW TO OBTAIN PAPER PLOTS}

For those having access to large-format plotters such as HP650C, HP755C, and HP2500C, plots may be made directly from the included plot file.

\section{DATABASE CONTENTS}

The files constituting the geologic map database of this Open-File Report are listed below along with the interchange files from which they were extracted.

\section{Data Package}

All files listed below are in a compressed tar file named els.tar.gz (2.1 Mb); see section below titled, SOFTWARE UTILITES.

$\begin{array}{lll}\begin{array}{l}\text { ARC/INFO } \\ \text { interchange files }\end{array} & \begin{array}{l}\text { Elsinore } \\ \text { coverages }\end{array} & \underline{\text { Contains }} \\ \text { els_geo.e00 } & \text { els_geo } & \text { Contacts, faults, geologic unit labels } \\ \text { els_ano.e00 } & \text { els_ano } & \begin{array}{l}\text { Annotation subclasses: } \\ \text { GEO (for plotting unit labels) }\end{array} \\ \text { els_str.e00 } & \text { els_str } & \begin{array}{l}\text { Leaders } \\ \text { Attitudes and their dip values. Dip values plotted } \\ \text { as annotation. }\end{array}\end{array}$

The directory, info/, is produced in the process of importing interchange files to ARC coverages in ARC/INFO. The els (Elsinore) info/ directory contains:

Feature Attribute Tables

Polygon attribute table

Arc attribute table

els_geo.pat

els_geo.aat

els_ano.aat

Point attribute table

els_str.pat

Annotation attribute table

els_ano.tatgeo 


$\begin{array}{lll}\text { Raster } & \text { Resultant image } & \text { Contains } \\ \begin{array}{ll}\text { file } \\ \text { els.tif }\end{array} & \text { Elsinore base map } & \text { Topographic base from } 500 \text { dpi scan of } \\ & & \text { USGS Elsinore } 7.5 \text { ' quadrangle, } 1953\end{array}$

\section{Plot Package}

PostScript plot files of the geologic map and explanation; please see section below titled, SOFTWARE UTILITIES for additional information.

Compressed file $\quad \underline{\text { Resultant image } \quad \text { Contains }}$

els_map.ps.gz els_map.ps

PostScript plot file of geologic map and $\mathrm{CMU} / \mathrm{DMU}$

The Postscript file is compressed using winzip.

The uncompressed Postscript file els_map.ps will plot a 1:24,000 scale, full color geologic map of the Elsinore quadrangle on the topographic base. A detailed CMU and DMU are included on the sheet. The sheet is in the editorial format of the U.S. Geological Survey's Geologic Investigations (I) map series, and is approximately $48 \times 36$ inches in size. The map sheet has been successfully plotted on Hewlett-Packard large-format plotters, models HP755C, and HP2500C.

\section{Symbols Package}

Files in the plot package have been prepared to produce optimum plots using the shade, line, and marker sets listed below; these symbol sets and supporting fonts are included in a compressed tar file named symbols.tar.gz ( $0.18 \mathrm{Mb})$; see section below titled SOFTWARE UTILITIES.

$\begin{array}{ll}\text { geoSCAMP2.lin } & \text { Lineset } \\ \text { geoSCAMP2.mrk } & \text { Markerset for points } \\ \text { alc1.shd } & \text { Colors } \\ \text { geology2.shd } & \text { Pattern fills } \\ \text { fnt026 } & \text { Font required for geoSCAMP2.lin } \\ \text { fnt037 } & \text { Font required for geoSCAMP2.mrk } \\ \text { fnt035 } & \text { Font required for geology2.shd }\end{array}$

Special geologic characters used in unit designations are from the Geoage font group and are contained in the geoage folder within the symbols.tar.gz file. The Geoage fonts are used in conjunction with the geofont.txt textset when using ESRI software. The geoage folder contains fonts, the geofont.txt textset, and explanatory files.

\section{Other files}

README.pdf

els_map.pdf
This document

Pdf plot file of geologic map and CMU/DMU

\section{SOFTWARE UTILITIES}

Files which have .gz file extension were compressed using gzip. Gzip utilities are available free of charge via the Internet at the gzip home page, http://www.gzip.org. Files with a .zip file extension were compressed using WinZip, available at http://www.winzip.com. 
The data package and symbols package are additionally bundled into a single tar (tape archive) file. The individual files must be extracted using a tar utility, available free of charge via the Internet through links on the Common Internet File Formats page, http://www.matisse.net/files/format.html. One such utility is WinZip, available at http://www.winzip.com.

\section{HOW TO OBTAIN THE DIGITAL FILES}

The export files, and subsequently the data and plot files, constituting the geologic map database of this Open-File Map may be obtained in two ways, both over the Internet.

1. The files can be obtained via the Web from Western Region Geologic Information Server. Go to the web page at http://geopubs.wr.usgs.gov/open-file/of03-281 and follow the directions to download the files.

2. The files can also be obtained by anonymous ftp over the Internet from wrgis.wr.usgs.gov. The files are located in the directory/pub/open-file/. Be sure to use binary transfer mode or ASCII mode for individual .e00 (ARC interchange file format) files.

\section{HOW TO EXTRACT THE GEOLOGIC MAP DATABASE FROM THE TAR FILE}

\section{Digital database}

After downloading the files, they must be uncompressed using a gzip utility such as gzip itself or WinZip. The data files must then be extracted using a tar utility or Winzip.

This process will create a directory, els/, that will contain the ARC/INFO interchange files and supporting files. The directory should contain the following files:

$$
\begin{array}{ll}
\text { els/ } & \\
& \text { els_geo.e00 } \\
& \text { els_str.e00 } \\
& \text { els_ano.e00 } \\
& \text { els.tif }
\end{array}
$$

The symbols.tar.gz file is imported using the same methods as for the els.tar.gz file. It will create a directory, symbols/ that will contain the following directory and seven files:

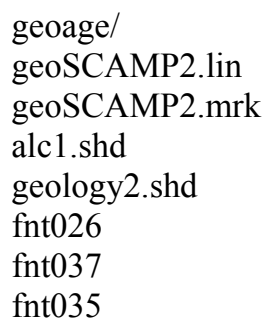


The following are not included in the database tar file, and are downloaded separately.

$$
\begin{aligned}
& \text { els_map.ps.gz } \\
& \text { README.pdf } \\
& \text { els_map.pdf }
\end{aligned}
$$

\section{Postscript plot files}

Make a 13.3 MB uncompressed file, els_map.ps (plot of complete map), by typing gzip -d els_map.ps.gz (or use gzip utility of choice).

\section{Portable Document Format (.pdf) files}

PDF files are not stored as gzip files. They are accessed using Adobe Acrobat Reader software, available free from the Adobe website http://www.adobe.com. Follow instructions at the website to download and install the software. Acrobat Reader contains an on-line manual and tutorial.

\section{HOW TO CONVERT THE ARC/INFO INTERCHANGE (EXPORT) FILES}

The ARC interchange (.e00) files are converted to ARC coverages using the ARC command IMPORT.

ARC interchange files can also be read by some other Geographic Information Systems, including ArcView (ESRI) and MapInfo (http://www.mapinfo.com), (Environmental Systems Research Institute, Inc., 1998). Please consult your GIS documentation to see if you can use ARC interchange files and the procedure to import them.

\section{DIGITAL GEOLOGIC MAP SPECIFICATIONS}

\section{Digital compilation}

The geologic map information was hand digitized from a base-stable original (ink on a greenline) of the geologic map at 1:24,000 scale. Digital tics were placed by hand at latitude/longitude intersections. The lines, points, and polygons were edited using standard ARC/INFO commands, and in some places, interactively by hand using graphical user interface ALACARTE (Fitzgibbon, 1991, Fitzgibbon and Wentworth, 1991, Wentworth and Fitzgibbon, 1991). Digitization and editing artifacts significant enough to display at a scale of 1:24,000 were corrected.

\section{Base map}

The base map image (els.tif) was prepared by scanning a scale-stable clear film of the U.S. Geological Survey, 1:24,000 Elsinore 7.5' quadrangle (1953) topographic map. Scanning was done using an Anatech Eagle 4080 monochrome 800 dpi scanner; at a resolution of 500 dpi. The raster scan was converted to a monochromatic image in ARC/INFO, and registered and rectified to the Elsinore 7.5, quadrangle. No elements of the base layer are attributed. The base map is provided for reference only.

\section{Spatial resolution}

Use of this digital geologic map database should not violate the spatial resolution of the data. Although the digital form of the data removes the constraint imposed by the scale of a paper map, the detail and accuracy inherent in map scale are also present in the digital data. The fact that this database was edited at a scale of 1:24,000 means that higher resolution information is not generally present in the dataset. Plotting at scales larger than 1:24,000 will not yield greater real detail, although it may reveal fine-scale irregularities above the intended resolution of the database. Similarly, although higher resolution data is 
incorporated at a few places, the resolution of the combined output will be limited by the lower resolution data.

\section{Map accuracy standards}

Until uniform National geologic map standards are developed and adopted, lines and points on SCAMP 1:24,000 scale geologic maps that are located to within 15 meters, relative to accurately located features on the base map, are considered to meet map accuracy standards. Dashed lines, indicated in the database as approximately located or inferred, are generally located within 30 meters, relative to accurately located features on the base map.

\section{Faults and landslides}

This database is sufficiently detailed to identify and characterize many actual and potential geologic hazards represented by faults and landslides, but it is not sufficiently detailed for site-specific determinations. Faults shown do not take the place of fault rupture hazard zones designated by the California State Geologist (see Hart, 1998).

\section{Database specifics}

General--The map database consists of ARC/INFO format coverages, which are stored in polyconic projection (Table 1), and a series of data tables. Digital tics define a 2.5 -minute grid of latitude and longitude in the geologic coverages corresponding to the 2.5 -minute tic grid on the topographic base map.

Table 1 --- $\quad$ Map Projection

Projection Polyconic

Datum NAD27

Zunits No

Units Meters

Spheroid Clark 1866

X shift $\quad 0.00000000$

Y shift $\quad 0.00000000$

Parameters $\quad-1171845.000$ longitude of central meridian 333730.00 latitude of projections origin 0.00000 false easting (meters)

0.00000 false northing (meters)

The content of the geologic database can be described in terms of feature classes that include lines, points, and areas that compose the map. See the metadata text file (Appendix I) for detailed descriptions.

Lines - Lines are recorded as strings of arcs and are described in an arc attribute (.aat) table. Complete lists of the line types (LTYPE) used in the quadrangle are available in Appendix I. They represent contacts and faults, which define the boundaries of map units and map boundaries.

Polygons --- Geologic map units (polygons) are described in the polygon attribute (.pat) table (details in Appendix I). For traditional descriptions of the map units, see the Portable Document Format file els_map.pdf or the Postscript map plot, els_map.ps. A list of all map units in the database is given in Appendix I. 
Points - Point information (attitudes of planar and linear features) is recorded as coordinate and related information. Complete lists of the point types (PTTYPE) used in the point coverage are available in Appendix I.

\section{REFERENCES}

Environmental Systems Research Institute, Inc, 1991, ARC/INFO command references 6.0: Proprietary software manual

Fitzgibbon, T.T., 1991, ALACARTE installation and system manual (version 1.0): U.S. Geological Survey, Open-File Report 91-587B

Fitzgibbon, T.T., and Wentworth, C.M., 1991, ALACARTE user interface - AML code and demonstration Maps (version 1.0): U.S. Geological Survey, Open-File Report 91-587A

Wentworth, C.M., and Fitzgibbon, T.T., 1991, ALACARTE user manual (version 1.0): U.S. Geological Survey Open-File Report 91-587C

\section{APPENDIX I (original metadata text)}

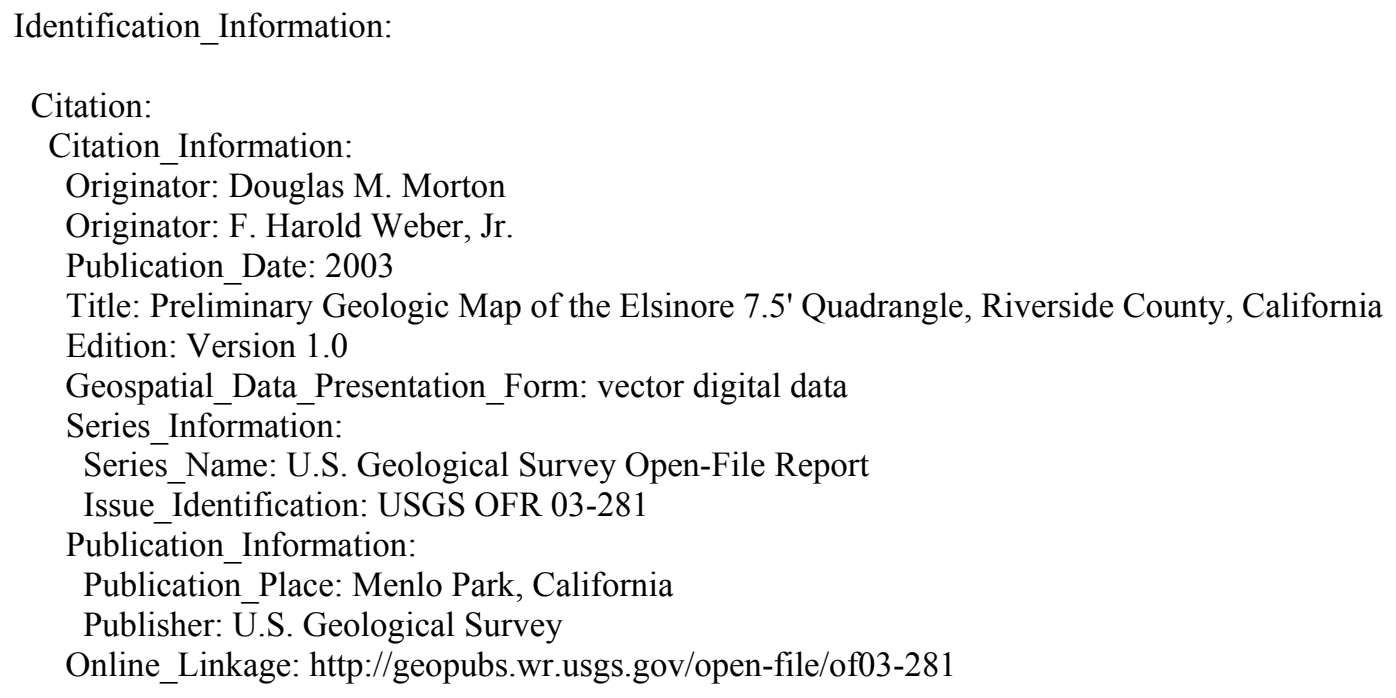

Description:

Abstract:

The Elsinore quadrangle is located in the northern part of the Peninsular Ranges Province and includes parts of two structural blocks, or structural subdivisions of the province. The active Elsinore Fault Zone diagonally crosses the southwest corner of the quadrangle, and is a major element of the right-lateral strikeslip San Andreas Fault system. The Elsinore Fault Zone separates the Santa Ana Mountains block west of the fault zone from the Perris block to the east. Internally both blocks are relatively stable and within the quadrangle are characterized by the presence of widespread erosional surfaces of low relief.

Within the quadrangle the Santa Ana Mountains block is underlain by undifferentiated granitic rocks of the Cretaceous Peninsular Ranges batholith, but to the west, includes widespread pre-batholithic Mesozoic rocks.

The Perris block is underlain by a combination of batholithic and prebatholithic rocks, the latter consisting of metasedimentary rocks of low metamorphic grade; sub-greenschist grade. The most abundant lithology is phyllite but includes locally thick sections of impure quartzite. Minor sills, dikes, and small elongate plutons of fine-grained hornblende gabbro intrude the phyllite. Thin layers of tremolite-bearing 
marble occur locally. Also local are thin layers of manganese-bearing rocks. Both rhodonite and manganese oxides occur in these layers. The phyllite has a regular northwest strike throughout the main body of metamorphic rock giving rise to a homoclinal section over 25,000 feet thick. The layeringschistocity of these rocks is transposed bedding and is not stratigraphic thickness.

In the northwest corner of the quadrangle is a series of Cretaceous volcanic and associated sedimentary rocks in the northwest corner of the quadrangle contain widespread primary sedimentary structures and appear to post date the metamorphism of the phyllite. The volcanic rocks are part of the Estelle Mountain volcanics of primarily rhyolitic composition. The sedimentary rocks are well indurated, perhaps incipiently metamorphosed, siliceous rocks containing local conglomerate beds.

Parts of three plutonic complexes are included within the quadrangle, all part of the composite Peninsular Ranges batholith. In the southeast corner is the northwest part of the Paloma Valley ring complex, which is elliptical in plan and consists of an older ring-dike and two subsidiary short-arced dikes that were emplaced into gabbro by magmatic stoping. Small to large stoped blocks of gabbro are common within the ring-dikes. A younger ring-set, made up of hundreds of thin pegmatite dikes, occur largely within the central part of the complex. Only the northern part of the older ring dike occurs within the quadrangle. Stoped gabbro masses occur near the southeast margin of the quadrangle.

In the northern part of the quadrangle is the southern part of the composite Gavilan ring complex of mostly tonalite composition. Hypersthene, although not usual in tonalite in the batholith, is a characteristic mineral of most of the rock of this complex. The Gavilan ring complex is a shallow intrusive that appears to be tilted up to the northeast. Fabric of the rocks changes in texture from hypauthomorphic-granular in the east to semiporphyritic in the west. The main part of the complex appears to have been emplaced by magmatic stoping. Several inactive gold mines, Goodhope, Gavilan, and Santa Rosa, are located within the complex.

Within the Gavilan ring complex is the south-half of the Arroyo del Toro pluton. This near circular-inplan pluton consists of massive-textured granodiorite that is essentially devoid of inclusions, and at one time was quarried for building stone.

The Elsinore Fault Zone forms a complex series of pull-apart basins. The largest and most pronounced of these pull-apart basins forms a flat-floored closed depression, La Laguna, which is partly filled by Lake Elsinore. This basin forms the terminus for the San Jacinto River. During excessively wet periods the La Laguna fills and the overflow passes through Warm Springs Valley into Temescal Wash which joins the Santa Ana River at Corona. La Laguna, bounded by active faults, is flanked by both Pleistocene and Holocene alluvial fans emanating from both the Perris block and the Santa Ana Mountains. North of La Laguna are exposures of the Paleocene Silverado Formation. Clay beds of the Silverado Formation have been an important source of clay. Overlying the Silverado Formation are discontinuous exposures of conglomeratic younger Tertiary sedimentary rocks that are tentatively correlated with the Pauba Formation.

Purpose: The data set for the Elsinore 7.5' quadrangle was prepared under the U.S. Geological Survey Southern California Areal Mapping Project (SCAMP) as part of an ongoing effort to develop a regional geologic framework of southern California and to utilize a Geographic Information System (GIS) format to create regional digital geologic databases. These regional databases are being developed as contributions to the National Geologic Map Database of the National Cooperative Geologic Mapping Program of the USGS.

Supplemental_Information: None

Time_Period_of_Content:

Time_Period_Information:

Single_Date/Time:

Calendar_Date: 2003

Currentness_Reference: New data

Status:

Progress: Complete

Maintenance_and_Update_Frequency: None planned

Spatial_Domain:

Bounding_Coordinates:

West_Bounding_Coordinate: -117.37509053

East_Bounding_Coordinate: -117.24990947 
North_Bounding_Coordinate: 33.74999995

South_Bounding_Coordinate: 33.62498421

Keywords:

Theme:

Theme_Keyword_Thesaurus: None

Theme_Keyword: geologic map

Theme_Keyword: geology

Theme_Keyword: bedrock geology

Theme_Keyword: fault

Place:

Place_Keyword_Thesaurus: None

Place_Keyword: California

Place_Keyword: Riverside County

Place_Keyword: Elsinore 7.5' quadrangle

Stratum:

Stratum_Keyword_Thesaurus: None

Stratum_Keyword: Cretaceous tonalite

Stratum_Keyword: Cretaceous granodiorite

Stratum_Keyword: Mesozoic metamorphics

Stratum_Keyword: Elsinore Fault

Temporal:

Temporal_Keyword_Thesaurus: None

Temporal_Keyword: Mesozoic

Temporal_Keyword: Cretaceous

Temporal_Keyword: Elsinore Fault

Access Constraints: None

Use Constraints:

The Elsinore 7.5' geologic-map database should be used to evaluate and understand the geologic character of the Elsinore 7.5' quadrangle as a whole. The data should not be used for purposes of sitespecific land-use planning or site-specific geologic evaluations. The database is sufficiently detailed to identify and characterize many actual and potential geologic hazards represented by faults and landslides and posed by ground subsidence and earthquake-generated ground shaking. However, it is not sufficiently detailed for site-specific determinations or evaluations of these features. Faults shown do not take the place of fault-rupture hazard zones designated by the California State Geologist (see Hart, 1988).

Use of this digital geologic-map database should not violate the spatial resolution of the data. Although the digital form of the data removes the constraint imposed by the scale of a paper map, the detail and accuracy inherent in map scale are also present in the digital data. The fact that this database was compiled and edited at a scale of 1:24,000 means that higher resolution information may not have been uniformly retained in the dataset. Plotting at scales larger than 1:24,000 will not yield greater real detail, although it may reveal fine-scale irregularities below the intended resolution of the database. Similarly, although higher resolution data is incorporated in most of the map, the resolution of the combined output will be limited by the lower resolution data.

Point_of_Contact:

Contact_Information:

Contact_Person_Primary:

Contact_Person: Douglas M. Morton

Contact_Organization: U.S. Geological Survey, Western Region, Earth Surface Processes Team

Contact_Position: Project Geologist

Contact_Address:

Address_Type: mailing address

Address: U.S. Geological Survey

Address: Department of Earth Sciences

Address: University of California, Riverside

City: Riverside 
State_or_Province: California

Postal Code: 92521

Country: USA

Contact_Voice_Telephone: (909)276-6397

Contact_Facsimile_Telephone: (909)276-6295

Contact_Electronic_Mail_Address: scamp@usgs.gov

Data_Set_Credit: Geologic mapping and digital preparation of this report were sponsored jointly by (1) the National Cooperative Geologic Mapping Program of the U.S. Geological Survey, (2) the California Geological Survey, and (3) the Southern California Areal Mapping Project (SCAMP).

Native_Data_Set_Environment:

SunOS, 5.7, sun 4 u UNIX

ARC/INFO version 7.2.1

Cross_Reference:

Citation_Information:

Originator: Morton, D.M.

Publication_Date: 1999

Title: Preliminary digital geologic map of the Santa Ana 30'x60' quadrangle, southern California, version 1.0.

Geospatial_Data_Presentation_Form: vector digital data

Series Information:

Series_Name: U.S. Geological Survey Open-File Report

Issue_Identification: USGS OF 99-172

Publication_Information:

Publication_Place: Menlo Park, California

Publisher: U.S. Geological Survey

Online_Linkage: http://geopubs.wr.usgs.gov/open-file/of99-172

Data_Quality_Information:

Attribute_Accuracy:

Attribute_Accuracy_Report:

Geologic-map units in the Elsinore quadrangle database were described using standard field methods. Consistent with these methods, the database author has assigned standard geologic attributes to geologic lines, points, and polygons identified in the database.

Nation-wide geologic-map accuracy standards have not been developed and adopted by the U.S. Geological Survey and other earth-science entities. Until such standards are adopted, the SCAMP project has developed internal map-accuracy standards for 1:24,000-scale geologic maps produced by the project.

Geologic lines and points on 1:24,000 scale geologic maps are judged to meet SCAMP's internal mapaccuracy standards if they are located to within $+/-15$ meters, relative to topographic or cultural features on the base map.

On any derivative geologic-map plot, line data that are judged to meet the SCAMP internal mapaccuracy standard are denoted by solid lines; line data that may not meet the SCAMP internal mapaccuracy standard are denoted by dashed or dotted lines. There is no cartographic device for denoting the map-accuracy for geologic-point data (e.g., symbols representing bedding, foliation, lineations, etc.). Logical_Consistency_Report:

Polygon and chain-node topology present.

The areal extent of the map is represented digitally by an appropriately projected (polyconic projection), mathematically generated box. Consequently, polygons intersecting the lines that comprise the map boundary are closed by that boundary. Polygons internal to the map boundary are completely enclosed by line segments which are themselves a set of sequentially numbered coordinate pairs. Point data are represented by coordinate pairs.

Completeness_Report: The geologic map database of the Elsinore 7.5' quadrangle contains new data that have been subjected to rigorous review and are a substantially complete representation of the current state of knowledge concerning the geology of the quadrangle.

Positional_Accuracy: 
Horizontal_Positional_Accuracy:

Horizontal_Positional_Accuracy_Report: The maximum transformation RMS error acceptable for a 7.5' quadrangle transformation and data input is 0.003 (1.8 meters). Horizontal positional accuracy was checked by visual comparison of hard-copy plots with base-stable source data.

Lineage:

Process_Step:

Process_Description: Field mapping and aerial photograph interpretation; iterative process (D.M. Morton).

Process Date: 1978,1998

Process Step:

Process_Description: Field mapping and aerial photograph interpretation; iterative process (F.H. Weber, Jr.).

Process Date: 1973-77

Process_Step:

Process_Description: Digitization of geologic linework and point data from a scale-stable cartographic base of quadrangle. ARC/INFO database established; cleanup of artifacts; polygon, arc, and point attribute tables established. Digitizing and editing artifacts significant enough to display at a scale of 1:24,000 were corrected (R.M. Alvarez and Diane Burns).

Process Date: 1999-2001

Process Step:

Process_Description: Description of map units and correlation of map units (R.M. Alvarez).

Process_Date: 2003

Process_Step:

Process_Description:

First draft of metadata created by R.M. Alvarez using FGDCMETA.AML ver. 1.2 05/14/98 on

ARC/INFO data set /scamp27/elsinore/els_geo

Process_Date: 20030319

Spatial_Data_Organization_Information:

Direct_Spatial_Reference_Method: Vector

Point_and_Vector_Object_Information:

SDTS Terms Description:

SDTS_Point_and_Vector_Object_Type: Point

Point_and_Vector_Object_Count: 296

SDTS Terms_Description:

SDTS_Point_and_Vector_Object_Type: String

Point_and_Vector_Object_Count: 749

SDTS_Terms_Description:

SDTS Point and Vector Object Type: GT-polygon composed of chains

Point_and_Vector_Object_Count: 297

Spatial_Reference_Information:

Horizontal_Coordinate_System_Definition:

Planar:

Map_Projection:

Map_Projection_Name: Polyconic

Polyconic:

Latitude of Projection Origin: 33.625

Longitude_of_Central_Meridian: -117.3125

False_Easting: 0.00000

False_Northing: 0.00000

Planar Coordinate Information:

Planar_Coordinate_Encoding_Method: coordinate pair

Coordinate_Representation:

Abscissa_Resolution: 1.0 
Ordinate_Resolution: 1.0

Planar_Distance_Units: Meters

Geodetic_Model:

Horizontal_Datum_Name: North American Datum of 1927

Ellipsoid_Name: Clarke 1866

Semi-major_Axis: 6378206.4

Denominator_of_Flattening_Ratio: 294.98

Entity_and_Attribute_Information:

Overview_Description:

Entity_and_Attribute_Overview:

Version 1.0 of the Elsinore 7.5' quadrangle comprises three ARC/INFO coverages, of which two contain geologic data, and one contains cartographic features: els_geo (geology), els_str (structural data), and els_ano (annotation and leaders).

Geologic data represented by line entities and the polygons they delineate are contained in the coverage ELS_GEO. For display purposes, the annotation coverage contains one annotation subclass: anno.geo contains unit labels.

Geological point data includes site-specific information describing the types and the orientation of bedding and foliation. Annotation is respective dip and plunge values associated with individual point data.

ELS_GEO.PAT:

\begin{tabular}{cccccc} 
COLUMN & ITEM NAME & \multicolumn{3}{c}{ WIDTH OUTPUT } & TYPE N.DEC ALTERNATE NAME \\
1 & AREA & 8 & 18 & $\mathrm{~F}$ & 5 \\
9 & PERIMETER & 8 & 18 & $\mathrm{~F}$ & 5 \\
17 & ELS_GEO\# & 4 & 5 & $\mathrm{~B}$ & - \\
21 & ELS_GEO-ID & 4 & 5 & $\mathrm{~B}$ & - \\
25 & LABL & 35 & 35 & $\mathrm{C}$ & - \\
60 & PLABL & 35 & 35 & $\mathrm{C}$ & - \\
95 & NAME & 100 & 100 & $\mathrm{C}$ & - \\
195 & SHD & 3 & 3 & $\mathrm{I}$ & - \\
198 & SHDFIL & 3 & 3 & $\mathrm{I}$ & -
\end{tabular}

ELS_GEO.AAT:

\begin{tabular}{cccccc} 
COLUMN & ITEM NAME & \multicolumn{3}{c}{ WIDTH OUTPUT } & TYPE N.DEC ALTERNATE NAME \\
1 & FNODE\# & 4 & 5 & $\mathrm{~B}$ & - \\
5 & TNODE\# & 4 & 5 & $\mathrm{~B}$ & - \\
9 & LPOLY\# & 4 & 5 & $\mathrm{~B}$ & - \\
13 & RPOLY\# & 4 & 5 & $\mathrm{~B}$ & - \\
17 & LENGTH & 8 & 18 & $\mathrm{~F}$ & 5 \\
25 & ELS_GEO\# & 4 & 5 & $\mathrm{~B}$ & - \\
29 & ELS_GEO-ID & 4 & 5 & $\mathrm{~B}$ & - \\
33 & LTYPE & 35 & 35 & $\mathrm{C}$ & - \\
68 & L-SYMB & 3 & 3 & $\mathrm{I}$ & -
\end{tabular}

Entity_and_Attribute_Detail_Citation: None

Detailed_Description:

Entity_Type:

Entity_Type_Label: els_geo.pat

Entity_Type_Definition: Geologic units (LABL) and their corresponding names (NAME) identified in the Elsinore $7.5^{\prime}$ quadrangle

Attribute: 
Attribute Label: LABL

Attribute_Definition: geologic map unit label, in plain text

Attribute Domain Values:

Enumerated_Domain:

Enumerated_Domain_Value: Qaf

Enumerated_Domain_Value_Definition: Artificial fill

Enumerated_Domain:

Enumerated_Domain_Value: Qw

Enumerated Domain Value_Definition: Very young wash deposits

Enumerated_Domain:

Enumerated_Domain_Value: Qf

Enumerated_Domain_Value_Definition: Very young alluvial-fan deposits

Enumerated_Domain:

Enumerated_Domain_Value: Q1

Enumerated_Domain_Value_Definition: Very young lacustrine deposits

Enumerated_Domain:

Enumerated_Domain_Value: Qyw

Enumerated_Domain_Value_Definition: Young alluvial-wash deposits

Enumerated_Domain:

Enumerated_Domain_Value: Qyf

Enumerated_Domain_Value_Definition: Young alluvial-fan deposits

Enumerated Domain:

Enumerated_Domain_Value: Qyf1

Enumerated_Domain_Value_Definition: Young alluvial-fan deposits, Unit 1

Enumerated_Domain:

Enumerated_Domain_Value: Qya

Enumerated_Domain_Value_Definition: Young alluvial-channel deposits

Enumerated Domain:

Enumerated_Domain Value: Qyv

Enumerated_Domain_Value_Definition: Young alluvial-valley deposits

Enumerated_Domain:

Enumerated_Domain_Value: Qof

Enumerated_Domain_Value Definition: Old alluvial-fan deposits

Enumerated Domain:

Enumerated_Domain_Value: Qof1

Enumerated_Domain_Value_Definition: Old alluvial-fan deposits, Unit 1

Enumerated_Domain:

Enumerated Domain Value: Qoa

Enumerated_Domain_Value_Definition: Old alluvial-channel deposits

Enumerated Domain:

Enumerated_Domain_Value: Qvof

Enumerated_Domain_Value_Definition: Very old alluvial-fan deposits

Enumerated_Domain:

Enumerated Domain Value: Qvoa

Enumerated_Domain_Value_Definition: Very old alluvial-channel deposits

Enumerated Domain:

Enumerated_Domain_Value: Qpf

Enumerated_Domain_Value_Definition: Pauba Formation

Enumerated Domain:

Enumerated_Domain_Value: Qpfs

Enumerated_Domain_Value_Definition: Pauba Formation, sandstone member

Enumerated Domain:

Enumerated_Domain_Value: Tcg

Enumerated_Domain_Value_Definition: Conglomerate

Enumerated Domain:

Enumerated_Domain_Value: Tsi 
Enumerated_Domain_Value_Definition: Silverado Formation

Enumerated_Domain:

Enumerated Domain_Value: Kgt

Enumerated_Domain_Value_Definition: Gavilan ring complex, massive textured tonalite

Enumerated_Domain:

Enumerated_Domain_Value: Kgh

Enumerated_Domain_Value_Definition: Gavilan ring complex, hypabyssal tonalite

Enumerated Domain:

Enumerated Domain Value: Katg

Enumerated_Domain_Value_Definition: Granodiorite of Arroyo del Toro pluton

Enumerated Domain:

Enumerated_Domain_Value: Kgbf

Enumerated_Domain_Value_Definition: Fine grained hornblende gabbro, Railroad Canyon area

Enumerated Domain:

Enumerated_Domain_Value: Kpvg

Enumerated_Domain_Value_Definition: Paloma valley ring complex

Enumerated_Domain:

Enumerated_Domain_Value: Kgd

Enumerated_Domain_Value_Definition: Granodiorite, undifferentiated

Enumerated_Domain:

Enumerated Domain Value: Kgb

Enumerated_Domain_Value_Definition: Gabbro

Enumerated_Domain:

Enumerated_Domain_Value: Khg

Enumerated_Domain_Value_Definition: Heterogeneous granitic rocks

Enumerated_Domain:

Enumerated_Domain_Value: Kvsp

Enumerated_Domain_Value_Definition: Santiago Peak Volcanics

Enumerated_Domain:

Enumerated_Domain_Value: Kvem

Enumerated_Domain_Value_Definition: Estelle Mountain volcanics of Herzig

Enumerated_Domain:

Enumerated_Domain_Value: Kvs

Enumerated Domain Value Definition: Intermixed Estelle Mountain volcanics of

Herzig(Cretaceous) and sedimentary rocks(Cretaceous)

Enumerated_Domain:

Enumerated_Domain_Value: Ksv

Enumerated_Domain_Value_Definition: Intermixed Estelle Mountain volcanics of

Herzig(Cretaceous) and sedimentary rocks(Mesozoic)

Enumerated Domain:

Enumerated_Domain_Value: Mzu

Enumerated_Domain_Value_Definition: Metasedimentary rocks, undifferentiated

Enumerated_Domain:

Enumerated_Domain_Value: Mzq

Enumerated_Domain_Value_Definition: Quartz-rich rocks

Enumerated_Domain:

Enumerated_Domain_Value: Mzp

Enumerated_Domain_Value_Definition: Phyllite

Enumerated Domain:

Enumerated_Domain_Value: Mzm

Enumerated_Domain_Value_Definition: Marble

Attribute:

Attribute_Label: PLABL

Attribute_Definition: Geological map unit label used to generate plot labels with relevant stratigraphic symbols. The geologic units with LABL designating Mesozoic (Mz) have keystroke substitute characters, \}, that call their corresponding symbols from the Geoage Font Group. Geologic map unit labels will plot 
on derivative map plots with appropriate stratigraphic symbols if PLABL is used as the source for unit labels.

Attribute:

Attribute_Label: SHD

Attribute_Definition: polygon color (as integer value) from shadeset alc1.shd

Attribute:

Attribute_Label: SHDFIL

Attribute_Definition: polygon fill pattern (as integer value) from shadeset geology2.shd

Attribute:

Attribute_Label: NAME

Attribute_Definition: Geologic name of map unit (see list under LABL attribute)

Detailed_Description:

Entity_Type:

Entity_Type_Label: els_geo.aat

Entity_Type_Definition: Geologic features such as contacts and faults that bound rock-unit polygons Attribute:

Attribute_Label: LTYPE

Attribute_Definition: Description of types of lines on the geologic map (contact, fault).

Attribute_Domain_Values:

Enumerated_Domain:

Enumerated_Domain_Value: contact, certain

Enumerated Domain:

Enumerated_Domain_Value: fault, certain

Enumerated_Domain:

Enumerated_Domain_Value: fault, approx. located

Enumerated_Domain:

Enumerated_Domain_Value: fault, concealed

Detailed Description:

Entity_Type:

Entity_Type_Label: els_str.pat

Entity_Type_Definition: Geological point data includes site-specific information describing the types and the orientation of bedding, foliation, joints, and lineations. One annotation subclass is included in the geologic points coverage, ELS_STR which displays the respective dip and plunge values associated with individual point data.

Attribute:

Attribute_Label: PTTYPE

Attribute_Definition: Describes type of point data (bedding, foliation)

Attribute_Domain_Values:

Enumerated_Domain:

Enumerated_Domain_Value: sedimentary bedding

Enumerated_Domain:

Enumerated_Domain_Value: igneous foliation

Enumerated_Domain:

Enumerated_Domain_Value: metamorphic foliation

Enumerated_Domain:

Enumerated_Domain_Value: vertical metamorphic foliation

Attribute:

Attribute_Label: PT-SYMB

Attribute_Definition: Coded integer value that relates point to cartographic point symbol in markerset geoscamp2.mrk

Attribute:

Attribute Label: STRIKE

Attribute Definition: Azimuthal strike of planar feature

Attribute:

Attribute Label: DIP

Attribute_Definition: Dip of planar feature 


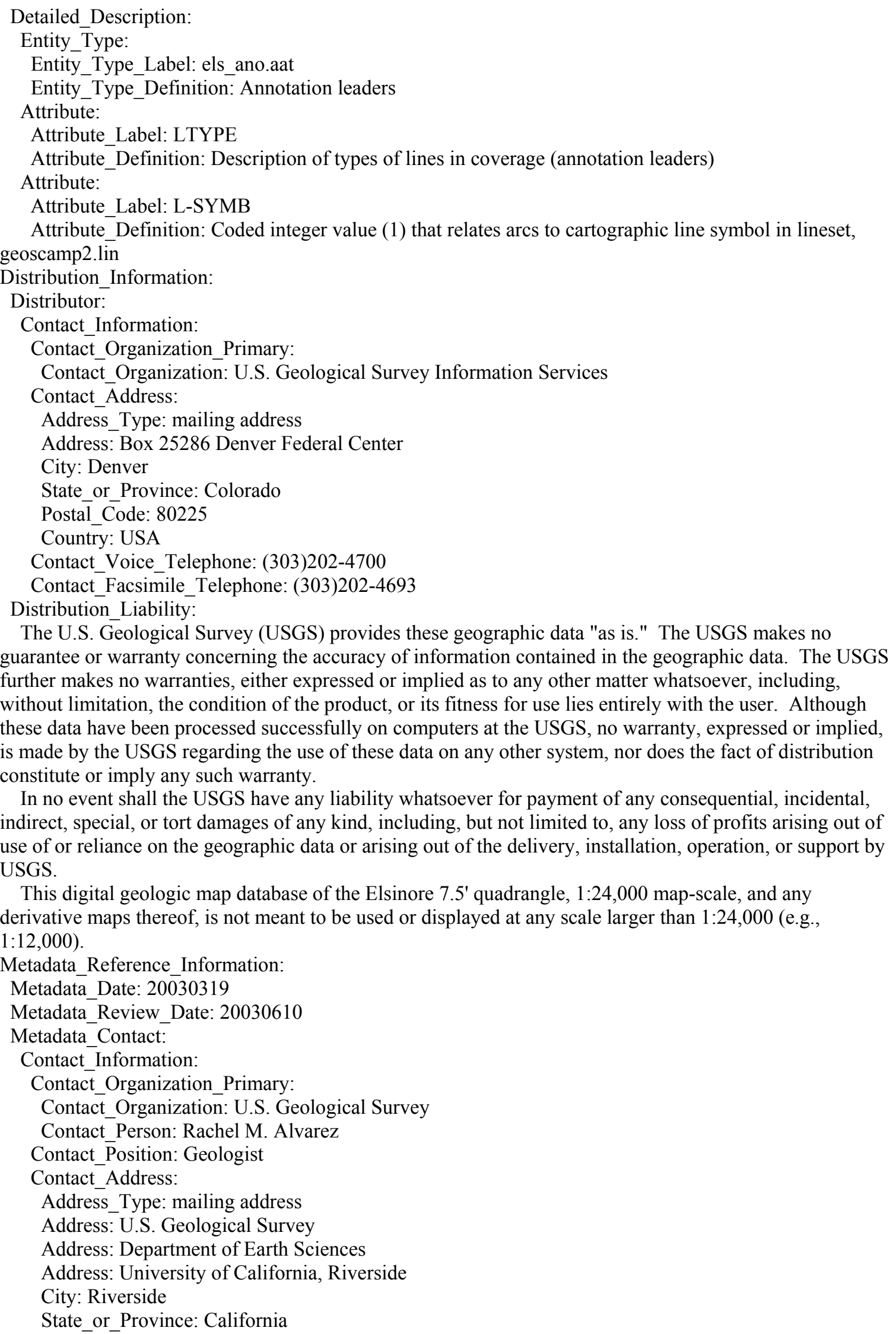


Postal_Code: 92521

Country: USA

Contact_Voice_Telephone: (909)276-6397

Contact_Facsimile_Telephone: (909)276-6295

Contact_Electronic_Mail_Address: ralvarez@usgs.gov

Metadata_Standard_Name: FGDC Content Standards for Digital Geospatial Metadata

Metadata_Standard_Version: FGDC-STD-001-1998

Metadata Access Constraints: None

Metadata_Use_Constraints: None 